\title{
Using Synchronous On-Site Computerized Testing To Match Assessment To Curriculum For Accounting And Information Systems Courses
}

\author{
John J. (Jack) Maher, (E-mail: jmaher@vt.edu), Virginia Tech
}

Kelly McNamara Hilmer, (E-mail: kmac@bus.ucf.edu), University of Central Florida

\begin{abstract}
Business practitioners and academics have identified computer literacy proficiency and technology-based integration as crucial abilities for accounting and AIS graduates to possess. We provide justification that synchronous on-site computerized testing (SOCT) examinations are invaluable for student assessment with respect to various types of AIS-related course material and offer a more appropriate matching of assessment with curriculum content than traditional examination methods. Evidence is supplied describing how SOCT techniques have been successfully applied in evaluating particular cognitive skills and computer abilities of recent accounting and AIS students.
\end{abstract}

\section{Introduction}

raduates in both accounting and accounting information systems (AIS) fields are expected to possess a certain minimum level of competency regarding technology and computer-related knowledge and skills involving networks, electronic commerce, databases, spreadsheets, and word processing (AAA, 2000; Davis, 1997). Accounting and AIS departments have increasingly incorporated the computer into the mainstream curriculum in an attempt to ensure graduates possess the necessary skills for successful use and integration of technology into their future professional career. We present here a case study describing the utilization of computerized testing to more appropriately match assessment of students to curriculum content.

While the essential technological skill requirements have changed dramatically over the past two decades, the primary means of individual student assessment has often remained relatively constant. Traditional paper-based examinations are still the predominant manner of testing applied in most on-campus universities. Although these exams are frequently supplemented with computerized take-home projects and assignments, the level of technological literacy of the individual student and the ability to apply appropriate software tools to solve complex tasks is rarely tested in a monitored computerized environment. In many educational situations involving AIS-related subject matter, synchronous on-site computerized testing (SOCT) environments can provide an invaluable method for motivating and ensuring that each student possesses the computer-related expertise and knowledge required by each professor for successful completion of the coursework. We present a case that describes the advantages and disadvantages of implementing SOCT techniques, as well as the important logistical considerations that must be handled during the process. We provide clarification as to why SOCT techniques provide a more appropriate matching of assessment techniques to actual curriculum content for certain AIS-related material. The rationale for this integration of computers with student assessment is derived from the repeated call from concerned parties such as employers for increasing computer and information system knowledge for accounting and AIS students.

Readers with comments or questions are encouraged to contact the authors via email. 


\section{Need for Computer Skills in Accounting and AIS}

Educators and practitioners have long recognized the importance of increasingly sophisticated computer knowledge and skills for graduates of accounting and AIS programs. The American Accounting Association has consistently recommended the use of computers in accounting education for over four decades (AAA, 1959; 1964; $1970 ; 1986 ; 2000)$. The largest professional services firms jointly issued a white paper describing the capabilities needed in accounting graduates (Arthur Andersen \& Co. et al., 1989). Included among these is the ability to understand the use of information technology in the accounting practice, as well as the knowledge to locate, access, and organize information from electronic sources. The Accounting Education Change Commission identified capabilities needed by accounting graduates and called for increased coverage of computers and information systems in the accounting curriculum (AECC, 1990).

A major research project, conducted jointly by the Institute of Management Accountants (IMA) and the Financial Executives Institute (FEI), identified multiple areas in which accounting education needed improvement. Two of the areas specifically recognized were overall computer literacy and better knowledge of information system design (Siegel and Sorensen, 1994). An Accounting Education Change Commission Monograph detailed a comprehensive range of specific areas of the accounting curriculum in which it is important to cover the various roles of information systems (AECC, 1996). An AICPA special committee on assurance services identified additional information system skills that accounting graduates should possess upon entry to the profession. Specifically mentioned were the need for skills in model building and an understanding of information technology (Elliott and Pallais, 1997).

In the overview of the AICPA Core Competency Framework for Entry into the Accounting Profession (AICPA 2001), the AICPA states that individuals entering the accounting profession must acquire the necessary skills to use technology tools effectively and efficiently. Furthermore, the AICPA lists necessary functional (i.e., technical) competencies. Among these competencies is the ability of individuals entering the accounting profession to be able to access appropriate electronic databases and use technology-assisted tools. The technology competencies also include the ability to build appropriate models using spreadsheets and other software.

Recently, a joint project of the AAA, AICPA, IMA, and the largest professional services firms clearly identified the critical need, as described by both practitioners and academics, of extensive information system coverage for current graduates (AAA, 2000). Furthermore, the project specifically recommended the inclusion of additional "broadening-type" information system courses into the accounting and AIS curriculum at both the undergraduate and graduate level. These, and many other authoritative bodies in various fields, have continually identified the importance of increasingly sophisticated technical knowledge and skills as an important graduation outcome. It appears only prudent that commensurate with this increase in technical knowledge and computer-related skills into the curriculum should also be a corresponding increase in the use of computers for assessment purposes of the relevant portions of the curriculum.

The remainder of this paper is structured in the following manner. The next two sections provide a brief background regarding various aspects of computerized testing methodologies, and then describe an AIS course that successfully employs SOCT techniques. Following this, we talk about student background and institutional considerations. Next, we discuss the SOCT task and administration. This is followed by a description of the advantages and concerns of SOCT techniques based on our experiences. Some logistical considerations unique to SOCT examinations are then described. Finally, the paper concludes with a brief discussion and summary comments concerning the appropriateness and effectiveness of SOCT techniques.

\section{Literature Review}

What is Computerized Testing?

Computerized testing has been around for many years. The basic term "computerized testing" has been used to describe a wide variety of procedures for using the computer for evaluation purposes. Sometimes referred to 
as computer-assisted testing or computer-based testing, it is the use of a computer in an educational setting as an aid in evaluating student performance (Stager and Mueller, 1991). In its most basic form of implementation, the term computerized testing can simply mean the assistance of computers in machine scoring of preprinted answer sheets. However, the term has a number of much more complex and powerful implications, such as individualized testing experiences, real life situational testing, and strength and weakness assessment (Stager and Mueller, 1991).

It is important to point out that our primary discussion of computerized testing (SOCT) is with reference to a situation in which students are located in one PC lab at the same time and are required to successfully complete a relatively complex examination using computer software as a tool to more effectively complete the task. As a specific frame of reference, we require the student to develop a customized, event-driven relational database business process application (e.g., Order Entry system). The professor provides a set of relational tables to the student who may then utilize all the available software and tools on the PC to develop a fully working application. At the end of a one or two-hour exam period, the student turns in a digital version of the completed business process application to the professor for evaluation and grading. In addition to being different from more elementary uses of the term computer testing, this type of environment should also be distinguished from asynchronous learning techniques and associated testing methods.

Asynchronous learning methods have become a popular way to administer various types of course content across the web to people in different locations. The basic concept is that individuals can learn what, where, and when they desire using computerized resources. For further information on asynchronous learning techniques see Jensen (2001). Assessment related to an asynchronous learning method is typically accomplished in a fashion similar to the delivery of the teaching material (i.e., offsite, non-monitored examination of the material). Our primary topic of interest, SOCT techniques, deals with applying computerized assessment techniques to a group of students at the same time in a single, monitored location.

\section{Who Uses Computerized Testing?}

Although the use of computers as a primary testing tool has not yet achieved widespread acceptance and use in higher education, this development has begun to make progress. For example, professors at approximately 100 institutions are using the Integrated Computerized Instructional Support System (ICISS) developed at ClarkAtlanta University. The ICISS system is used for note taking, tutorial purposes, and testing (Treadway, 1998). The system prepares students by showing multimedia presentations of course topics and providing interactive questions geared towards a variety of learning styles. Computerized testing is also used in various countries. The School of Computing at Wolverhampton University, in the United Kingdom, has been experimenting with computer-assisted testing in many different facets of their curriculum. Wolverhampton's math, statistical, and information technology departments, as well as diagnostic tests for programming, have effectively used computers in their testing for multiple years (Thelwall, 2000).

The Graduate Management Aptitude Test (GMAT) has been administered in a monitored computerized testing environment to prospective graduate students in business since October 1997. The GMAT exam is required for entrance to most graduate business schools in the United States. The AICPA has recently issued an Exposure Draft (AICPA, 2001) describing important changes in the structure and content of the Uniform CPA examination. These changes include switching to an entirely computer-based examination format as of November 2003. It will be very advantageous for accounting and AIS students to have experience with computerized testing environments prior to taking a major exam.

At our University, we have been applying SOCT techniques successfully to senior-level accounting and AIS majors in semester-long (15-week) courses for over seven years. The assessment techniques described here are also utilized in one of our sophomore level courses, Personal Computers in Business. Additionally, these same concepts and methodologies can easily be applied to a variety of courses in different disciplines. 


\section{Description of AIS Course Employing SOCT Techniques}

Although both accounting and AIS majors are housed in the same Accounting and Information Systems (ACIS) department in our college, the description we provide regarding coursework and prerequisites is geared toward our "mainstream" accounting major. These mainstream Accounting majors are required to take one information system course in each of their four years. Courses taken in the first three years provide a foundation in current computer and technology concepts, as well as proficiency in the fundamentals of utilizing Microsoft Office. Students also learn the basics of structured system development techniques, and cover accounting and business processing cycles. The fourth and final systems course required of accounting majors is given during the senior year (ACIS 4504- Accounting Application Development) and is the class in which we describe the use of SOCT techniques.

ACIS 4504 specifically concentrates on developing customized, event-driven accounting and business process applications in a relational database environment utilizing proper accounting controls. The primary software package employed in the past few years has been Access, the relational database component of the Microsoft Office suite. Visual FoxPro and Visual dBase have also been used previously in the class. Although we refer to Microsoft Access when necessary to make specific references throughout this paper, SOCT techniques can be applied using a wide range of software. Relational databases are just one of many potential application areas.

The ACIS 4504 course is designed to be held $80 \%$ of the time in a personal computer (PC) lab, and students are provided significant hands-on cognitive and practical skill development during the semester. Throughout the first half of the semester, students are required to develop a series of individual projects to further de velop their database application development skills, as well as their theoretical knowledge base. During the second half of the semester they must ultimately develop a customized event-driven relational database system to handle a specific business process system (e.g., Order Entry/Revenue, Purchasing/Expenditure) for their selected company.

The class itself is considered a capstone AIS-related course that allows accounting students to integrate a variety of knowledge from previous courses in carrying out their group projects. To successfully complete the class, students must demonstrate their individual ability to knowledgeably work with relational databases, design and develop properly controlled business process systems, and demonstrate their proficiency with computerized relational database tools and software. The SOCT methods utilized in this course provide an appropriate matching of assessment techniques with curriculum content and help us to confidently evaluate mastery of the desired concepts and skills. This is particularly useful in light of recent technological advances in computerized software tools that incorporate increasingly powerful wizards and experts that permit a user to complete a project more efficiently and effectively.

\section{Student Background and Institutional Setting Considerations}

In structuring effective accounting and AIS curriculums, it is important to consider the prerequisite courses completed by the students. This consideration also holds true when designing effective assessment techniques. It could be imprudent to utilize computerized testing methods with first or second semester freshman when you do not have evidence that all the students have the required keyboarding, operating system, and application skills necessary to effectively function in such an environment. Providing a computerized exam in this type of environment for the first time may actually be a dual test that measures the student's ability to work in a computerized environment, as well as measuring his/her knowledge of the actual subject matter. Conversely, a student in an upper-level AIS course who has previously been required to complete multiple computer assignments could be expected to effectively function in such a computerized setting. The professor should be able to utilize the computer as an effective assessment tool of the desired subject matter.

Another factor to consider in establishing SOCT techniques is the general computer literacy of the overall student population. Many schools now require all students to purchase personal computers upon entry into the university. In fact, some schools (such as Wake Forest University) even include the cost of the computer as part of tuition and issue a laptop computer to the student at the beginning of the first semester. The laptop is then traded back 
to the university after two years, and replaced with a current model. This level of commitment to computer integration and the accompanying attitude toward technology permeates the students' lives and fosters a high level of technological literacy. This would clearly help to facilitate the implementation of SOCT techniques. Some universities fall at the other end of the computer integration spectrum. A professor teaching at this type of campus would be wise to ensure the students have reached a certain minimum level of technological proficiency before engaging SOCT techniques. Conducting multiple class sessions in the PC lab can help attain this level of confidence.

The institutional setting also encompasses various factors that need to be taken into account when considering the appropriateness of SOCT techniques. Perhaps most important is the nature of the computer facilities available to the professor to offer computerized testing. If the university does not provide a certain minimum level of PC lab resources with respect to hours of lab availability, number of computers, type and currency of software, technical support, etc., then it would be difficult for a professor to utilize SOCT. Certain shortcomings can be worked around, but it makes the task more difficult to logistically undertake.

\section{SOCT Task and Administration}

\section{Exam Task}

To complete the computer-based portion of our exam, students are provided a digital copy of an instructordeveloped Access database containing several data tables (see Figure 1 for an example of sample tables). Students are then required to develop customized event-driven entry forms (including writing some VBA code), various queries, output reports, and a menu that will run the overall system.

Figure 1

Screen-shot from Access showing the Relationships window view of four relational tables involved in the revenue business processing system.

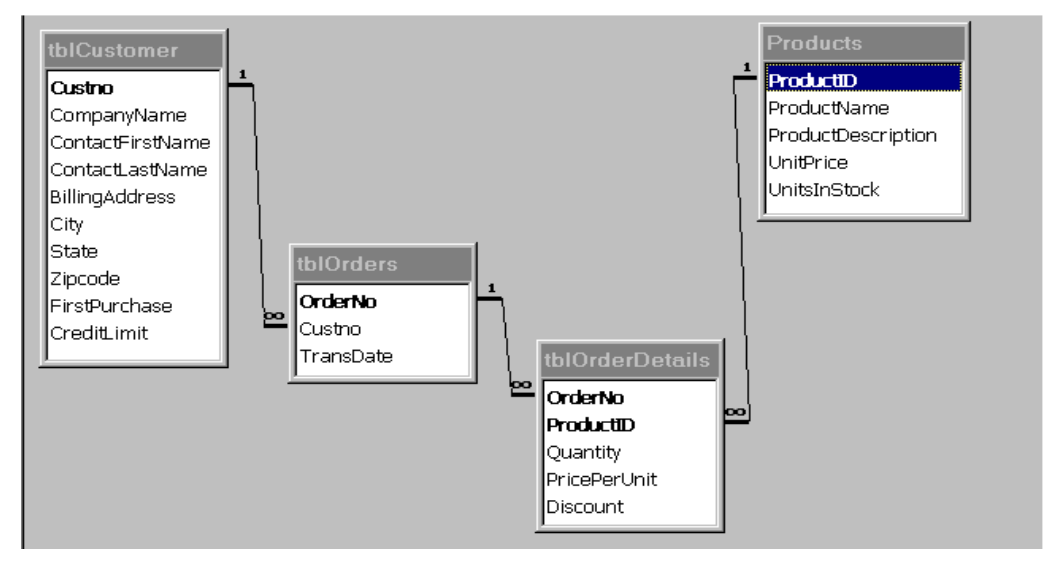

The exam is time-constrained and students are encouraged to complete the exam in sequential order from beginning to end. The exam is designed in such a way that points are increasingly difficult to obtain as the student advances further into the exam (i.e., each single point towards the end requires more time and effort than those at the beginning). The purpose of this strategy is to allow the majority of the students to achieve at least a certain minimum number of points (e.g., a $\mathrm{C}$ grade) if they have obtained a baseline understanding of the concepts and practical computer skills. The better students will achieve this level more expeditiously and proceed further in completing the exam. It is important to note that the exam is designed in such a way that typing speed is not a major issue. The real advantage comes with knowing how to utilize the available tools to apply them to a conceptual task in an efficient manner. This process is likely to be similar to the situation many students will find themselves facing in their professional work environment. 
Establishing the proper length and level of difficulty for any type of exam is always a challenge and this is especially true with computer-based exams. If the exam is too short or easy, virtually everyone will achieve a perfect score. If the exam is too hard, students will perform poorly and get extremely frustrated. It takes some experience to accurately gauge what the students can reasonably manage during the computerized exam period, but the instructor will become more accurate each exam.

\section{Administering the SOCT Exam (Instructions to Students)}

Students are provided with specific instructions (see Table 1) upon entering the PC lab to take the exam. The instructions have been designed to minimize the possibility of certain problems occurring that we have anticipated or encountered in the past.

Table 1: Exam Instructions to Students

Sit at your assigned computer (see $\mathrm{O} / \mathrm{H}$ for seat).

Do all work under designated folder (directory) on your PC.

Save your work frequently to the hard drive (every 5 minutes).

Save your work to your diskette every 15 minutes. (Open Windows Explorer in second window and minimize.)

At end of exam, make $T W O$ copies of completed database to diskette. (Ensure name is on diskette.)

Erase folder, empty recycle bin.

Turn in diskette to instructor with hard copy of your exam material.

The first instruction, sitting at designated computers, is designed to minimize the possibility of cheating. Although we believe the vast majority of our students (and college students in general) are honest, we believe that some small percentage of students would be tempted to cheat when put into certain situations. Sitting at assigned computers, with the specific computer unknown to the students prior to the start of the exam, effectively minimizes the potential for two dishonest actions. First, students will not pre-arrange to sit next to a buddy who will work in such a manner that they will be able to view the partner's monitor during the exam in trouble spots. It is still possible that they could look at their neighbor's machine even with assigned seats, but students are usually moving relatively quickly during the exam from screen to screen and it's difficult to follow a complex process that quickly changes screens with single mouse clicks. Second, assigned seating reduces the possibility that a student will get to a specific exam PC in advance and store potentially useful data on the hard drive.

The purpose of the second instruction, having students work in a designated folder, is designed to make it easier for the after-exam process of searching and cleaning each PC of the exam files. This would not be an important concern if your specific PC lab has an automated process available to bring each PC lab machine back to a "standard" configuration (i.e., hard drive contains no extra exam files).

Instructions three and four (i.e., urging the student to save frequently on the hard drive and also on the diskette) help ensure that the student will not lose much work in the event of a hardware failure or computer freezeup. Students should do this as second nature by the time they are in upper-level classes, but it is important to remind them.

The purpose of instruction five, saving two copies of the completed exam, is to help ensure that the professor will have a digital version of the exam that can be graded. It is even safer to require two different diskettes in order to avoid the possibility of complete diskette failure.

Instruction six, erasing folders and emptying the Recycle Bin, gets the students to help in cleaning up the exam computer of the most visible remnants of their exam files. Of course, it must be noted that the actual files the students develop are not removed from the hard drive until the specific disk clusters are physically overwritten. Password protecting the distributed exam file can help provide another layer of security. 


\section{Possible Methods for Distribution of Exam File(s)}

There are several methods available to distribute the digital exam database to the students. The most efficient and desirable procedure will often depend on the individual PC lab network setup, as well as the professor's preference. One option is to store the database in each machine's designated folder sometime shortly in advance of the exam. Alternatively, you could distribute the file via the network directly to the student machines at the start of the exam. If you use the network distribution option, you should then disable the communications feature for all machines. You could do this through a supervisor software control, if installed in your lab, or you could simply unplug the Ethernet cable from the back of each of the PC's once they have obtained the necessary files. If you do not disable the communications feature, you should have a detailed (i.e., machine by machine) PC lab communications $\log$ available. You could then look for any communication between students during the exam in order to detect any unusual transactions or transferring of files (e.g., either from one student to another or to/from an outside site). Perhaps the easiest exam distribution method is to simply include necessary files on a student diskette that is collected in advance and distribute these at the beginning of the exam period.

\section{Advantages of SOCT Testing Environment}

The benefits of using computerized testing are substantial. These are briefly summarized in Table 2 , which describes some of the basic advantages of allowing students to utilize all the typical computerized tools at his/her disposal when solving complex business problems. Importantly, computer-assisted testing comes much closer than traditional testing methods in allowing the student to work as if he/she were solving a problem in an everyday business setting. For those courses whose content deals with computer applications or systems, the students can often be tested more effectively and efficiently using personal computers and software rather than only answering objective and/or essay questions. This can provide a better matching of the assessment method with the content of the course than traditional testing methods. In addition to providing a more realistic assessment environment, research has shown that computerized testing is viewed as both faster and more rewarding than that of traditional pencil and paper testing (Cardwell, 2000).

Table 2: Advantages of SOCT Testing Environment

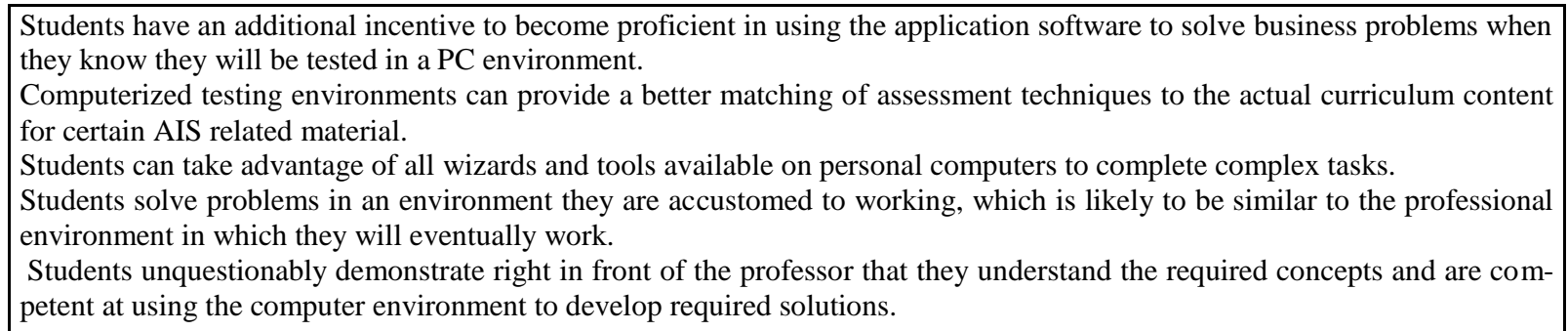

Perhaps the most useful advantage of utilizing SOCT exam techniques is that students, when clearly informed of the course exam requirements, will properly prepare themselves for it. It should be openly announced at the beginning of the course (e.g., on the syllabus) that the exam(s) will be conducted on the PC in the computer lab. This forewarning provides a clear incentive for students to ensure in advance that they are proficient with the computer system and application software they will be using during the exam.

Today's computer software packages contain a wide variety of exceptionally useful wizards, tools, content specific help, and other efficiency enhancing components. Students will have these productivity tools readily available to them in their everyday professional lives to help increase their effectiveness and efficiency in their jobs, therefore it's prudent to incorporate them into students' work. It is difficult to decisively determine an individual student's ability to apply these tools to help solve both conceptual and practical problems without observing them in a SOCT situation. In our testing example, a student is able to produce a reasonably significant portion of a relatively 
modest, but complete, revenue processing system for a business including required customization using VBA code segments. The student is provided with a base set of tables (files) that need to be manipulated and properly related (joined). The ability to establish different types of join relations between multiple tables is now a simple drag and drop operation that can be executed in a mere second or two. Of course, this requires that the student understands the relational concepts accurately, and also knows how to utilize the software tool correctly. Assessing a student's ability to complete this type of complex assignment in a relatively short period can best be accomplished in a SOCT exam environment. A traditional paper-based environment would only provide incomplete segments of the overall ability.

An analogy regarding the continual evolution in the auditing profession may be useful in explaining our position on this matter. Prior to widespread incorporation of Computer Assisted Audit Techniques (CAAT) into the audit process, auditors were required to depend heavily on individual hand sampling of transactions to discover evidence of particular problems (e.g., accurate extension (multiplication) of fields within a transaction and the proper posting of that transaction). With the incorporation of CAAT, the auditor can confidently assess the mathematical accuracy of every single transaction for the year and check that each amount has been properly posted. Further evolution of technology and tools in the auditing profession has resulted in the incorporation of real-time audit modules being incorporated into the client's transaction processing system to "observe" and gather sample transactions as the system actually performs its function each day. Although this is just one portion of the overall audit process, it helps to provide more confidence in the results of the audit of the transaction processing system. In a similar vein, a traditional paper-based exam for certain AIS related material provides only a small sampling of the student's skills and knowledge. It does not provide comprehensive evidence regarding the individual student's ability to work with the conceptual and cognitive complexities of customized relational database business processing systems. Paper-based exams also do not give a realistic picture of how each student actually works in a PC environment in solving complex AIS related problems. SOCT techniques, although still a sampling method, provide a more comprehensive view of the overall capabilities of each student working on a complex AIS related task.

Students demonstrate right in front of the professor's eyes that they are competent in the PC environment in developing customized relational database business applications. Their knowledge and skills are unequivocally demonstrated during the exam. Students are often elated when they get it right. Correspondingly, they may also get frustrated when they don't get it perfect. The SOCT environment exposes the best and worst of their abilities.

\section{Potential Concerns}

In addition to the important advantages of using SOCT, there are also some potential concerns to consider relating to the students, the instructor, and the computer itself (see Table 3). Most of these problems are relatively minor and can be easily handled with a little foresight and a plan of action developed by the instructor. However, failure to anticipate and plan for some of these problems could result in a minor problem becoming much larger for the professor.

\section{Table 3: Potential Concerns Related to SOCT Environment}

Student stress (for some students more stress than traditional testing methods). Time constraint also puts extra pressure on some students.

Instructor stress in administering the exam. (It's much easier to hand out a written exam and observe).

Machine hardware/software failure. (Be sure to have extra PC's available for problems).

Potential to look at neighbor's screen (Usually students are working too fast moving from screen to screen).

Exam grading process (If it works, great. If not, you must attempt to find out why. Could be a simple error, or it could be the entire logic is wrong or even missing).

Differentiation of A, B, C, D students (not always clear, same as traditional).

What to do if/when student's diskette fails while grading.

Student and Instructor Stress 
One disadvantage of the SOCT environment is the potential for increased student stress and anxiety level during the exam, particularly for those students that are encountering computer-specific problems. Interacting with a machine, even a familiar PC, in an exam situation seems to put some students at a higher level of stress than traditional written exams. A time constraint also adds extra pressure on some students. If students are using the computer for assignments, then taking a test that is somewhat similar to the assignments will help them be more at ease. Additionally, explicitly announcing at the beginning of the semester that exams will be on the computer helps to establish expectations and prepare students for the eventual task.

Another disadvantage of the SOCT environment is the phenomenon of increased instructor stress in administering the exam. It is far easier to simply hand out a written exam, answer an occasional question, and wait for the students to complete it. Frequently, during SOCT exams, the instructor is required to move through the students to troubleshoot a variety of problems that crop up. One major problem area we have occasionally experienced is machine/software failure, which is especially annoying to students. He/she typically turns to the instructor for help when the computer freezes up or "hangs." After trying to troubleshoot, you may have to reboot the machine. In our PC lab, this entails waiting for the PC to go through the normal boot-up process, and then the machine must go through an automated virus scan. In addition, because the machine did not shut down properly, a scan-disk procedure may be required. In reality, this sequence typically takes two minutes or so, but to the student it seems like an eternity. The best method of dealing with this may be to simply remind the student about the basic process and that it will take just a few minutes. Fortunately, after installing the Windows 2000 operating system in our lab, we have had far fewer freeze-ups then previously.

\section{Software/Setup Problems}

It is wise to conduct some pre-screening of the PC's to ensure all the necessary exam software is installed properly and none of the files or settings have been altered in such a way as to cause problems during the exam. If your class meets regularly in the lab, you can get the students to help by performing a few simple checks. Any problems can be reported to lab personnel and fixed before the exam. Some basic software considerations to check on each machine include (using Access software as the example):

* Is the basic software installed with all the desired wizards available? It is possible to omit or remove certain wizard features in some setup procedures.

- Are all the help files installed? A useful and extensive help support system can be found in Access, as well as in Visual Basic. Because a readily available help system is one of the realistic advantages of computer use and the SOCT environment, you should ensure that all desired help files are available on each machine.

* Is a default printer installed for reports? This is important even if you will not print anything. If you wish to preview reports on the screen, you must have default printers established. Otherwise, you will not be able to run reports without going through the print setup routine and identifying the actual type of printer that particular PC is connected to. This can be challenging for a student in the middle of an exam.

\section{Hardware Problems}

It is also possible to encounter a variety of hardware problems. One awkward situation involves hardware failure of critical components that would require substantial time and effort to replace such as the hard drive, diskette drive, processor, monitor, etc. It is essential that you have at least one or two extra machines available as backups in case some type of failure occurs and you can't troubleshoot and solve the situation in a short period of time. We recommend at least two or three extra machines for every twenty students, but this number will depend on your experience of the historical reliability of the specific lab equipment and the availability of computers.

When a major hardware or software failure occurs for a student and you have extra machines available, you can simply have the student take his/her disk to one of the extra PC's in the lab and he/she can continue working while losing very little time. The alternative, when no extra machine is available, is a complete disruption of the situation with the student unable to continue working. At this juncture, the basic alternatives are not particularly appealing. Some possibilities include having the student return right after the exam period is over to continue the test- 
ing. This is not very realistic because he/she may have another exam (or another important commitment) scheduled for that time. In addition, the student has now worked with the actual exam content. Another non-optimal alternative is to simply have the student stop working and grade him/her on what has been completed. We strongly recommend having extra machines as backups to alleviate this possibility.

\section{Grading Considerations}

Grading a SOCT exam shares certain common characteristics with traditional exams, but also possesses several unique attributes. Similar to traditional examination methods, the problem exists of differentiation between A, B, C, D and F students. This is not always clear and reasonable professional judgment is often required, similar to grading essay-type questions. As with paper-based methods, the grading process is very quick when the student does very well. SOCT grading can be even quicker than most essay/short-answer handwritten grading for correct answers. In our Access exam example, we run the system from the student-developed menu, enter a few test transactions, and examine the output. If correct, that particular component is completed. Of course, it's much more time consuming to grade incorrect portions on SOCT exams, just as it is with subjective paper-based exams that allow for partial credit.

When an error occurs with SOCT, the professor must investigate the extent and location of the error. Using our Access accounting application development example, assume we require a command button with customized VBA code on an order processing input form is required. The button should add a record to the Customer Transactions table and update the Units-in-Stock field in the Products table. However, when you grade it, a student's update button does not work properly. The potential cause could be that the student simply did not write any code at all for the button. More likely, there would be code containing a varying amount of logic and/or syntax errors. Another potential cause of this error could be that the code is written properly for the button, but the underlying tables have not had relations established properly. These conditions may seem like a grading nightmare, but the professor can quickly adapt to the process and learn how to become more efficient. It has been our experience that these types of errors can be categorized reasonably quickly, based on severity, into a systematic deduction of points.

One potential grading problem that is fairly unique to computerized testing methods is what to do if/when a student's diskette fails while grading. Earlier, we recommended having two copies of the exam file be placed on the exam diskette or even two diskettes from each student. One potential solution is to consider checking that the files are readable on an instructor machine as the students' hand them in at the end of the exam. This would require a somewhat extended "check out" process at the end of the exam period. Even with this precaution, there still exists the possibility that one or both files are corrupted. Although very unusual, the professor should give some forethought as to what approach should be taken. Some possibilities we have considered include the following:

* Have the student take the test again (often not very practical).

* If your exam is half written and half SOCT based, calculate the overall grade using the written portion.

* If you give multiple SOCT exams throughout the course, give the student the average grade he/she received in the previous SOCT portions.

* Give the student the average grade the overall class received on the SOCT portion of this particular exam. If this procedure results in the student just missing a border cutoff in the final grade process, perhaps it would be best to give the student the benefit of the doubt.

In any event, should irreparable corruption happen to the files, the professor will have to use his/her professional judgment as to which approach is best given the overall circumstances. You should think about the possibility of this situation in advance of the exam and what your strategy might be to arrive at a solution. Even considering the potential problems and logistical considerations that must be taken care of when using SOCT techniques, we feel the advantages outweigh these problems for the type of AIS course we teach and provide a more appropriate assessment technique that better matches the curriculum content than traditional paper-based examinations.

\section{Logistical Considerations in Administering SOCT Exams}

In this section we describe some logistical considerations when administering the SOCT exam (see Table 
4). By way of example, these are geared to our particular lab environment, but similar concerns are likely to be found at many university PC labs. The first fundamental concern that the professor must deal with is obtaining a PC lab reservation well in advance of the designated exam period. If the PC lab is not available during the regular class period, you may have to schedule the exams for an alternative time such as at night.

Table 4: Logistical Considerations

I. Preparation in advance of exam (e.g. one week).
a) Ensure that you have extra machines available to handle unexpected problems.
b) Can obtain blank formatted diskette from students in advance and load exam database on it. Alternative is to distri-
bute from file server on day of exam then disable or monitor any student communications.
II. Preparation of exam machines (e.g. day of the exam).
a) Remove all potentially undesired files left from previous students or classes.
III. Administering exam.
a) Assign students to seats upon entering exam room (put seating chart on $\mathrm{O} / \mathrm{H})$.
b) Collect diskette(s) containing two copies of the completed assignment.
IV. After completion of exam period
a) Clean machines after each exam prior to next group of students. Alternative is to utilize a different database and
password for each group.

Preparation in Advance of Exam (e.g., One Week)

You should ensure that you have extra machines available to solve major hardware/software problems. You can also obtain blank formatted diskettes in advance with each student's name so they can use it during the exam. You might consider having someone (e.g., a graduate assistant) ensure they are blank. Another alternative is to recycle the diskettes from the previous semester's exam (after removing the completed files). You can copy the exam file(s) onto the diskette to be distributed to the students. We suggest using a filename that is not suggestive of exam material (e.g., temp25) and utilize a reasonably obscure password (e.g., something with letters and numbers). This provides some additional protection against the unlikely event that a digital copy somehow gets distributed past your exam security procedures. The password also provides some protection in case future students somehow discover a leftover version of the exam database (e.g., on a lab machine). This approach is not foolproof, but provides a reasonable degree of protection.

Preparation of Exam Machines (e.g., Day of the Exam)

On the day of the exam, someone should remove all potentially undesirable files left over from previous students or classes. Using Access as our application example, remove all .mdb files, except the Northwind database that ships with Access, from each machine and empty the recycle bin. This would not detect database files that were renamed with a different extension, but we believe the risk of this type of intentional advance cheating is minor; particularly if the students do not know which PC they will be assigned to during the exam. Another task that can be performed the day of the exam is to load the exam databases onto each machine via the network. This assumes you decided not to collect and prepare exam diskettes in advance for the students.

\section{After Completion of Exam Period}

Someone should "clean" the machines after each exam group exits the room. If you have a network with an instructor workstation that has permissions set to share each of the lab machines, you could do this from a single location. Alternatively, you may have to clean each individual machine. Under these conditions, we suggest getting the students in the prior class to help, as described earlier. An alternative to cleaning each machine between contiguous groups is to give the exam file different names and passwords for the different groups. You can then distribute the diskettes to the second class with the different filename. Alternatively, the different files can be stored in 
separate folders on each machine's hard drive before the start of the first exam. This helps alleviate the transition stress of changing from one group to another.

In our PC lab environment, it is possible, even likely, that a professor could administer an exam in the morning and then have a different group of students from an unrelated class enter the room immediately following the completion of your exam in order to use the machines for their exam. We might then have to give another section our exam that afternoon or possibly a few days later. Therefore, it is advantageous to have a previously designed, well-developed distribution and cleanup process established in advance.

\section{Discussion and Summary}

One practical question not yet addressed here is the issue of providing students unlimited access to the Internet during the examination period, or restricting students to the information on the local PC. Allowing freedom to utilize available sources on the web to help solve the problem most closely resembles the environment in which the students will ultimately work. However, this freedom brings with it many examination integrity and security issues. At the very least, a professor adopting this sort of wide-open approach will need to develop substantially different examinations each semester. Otherwise, an astute student could easily store solutions to prior exams on a web site to be downloaded and manipulated during the exam.

Freedom to use the web also raises the issue of electronic communication with other individuals outside (or inside) of class for assistance during the exam period. Most professors would not consider allowing their students unlimited access to outside authorities during an examination. There are many intermediate approaches possible to help solve this problem. One is to supply a prescribed amount of information to the student in a digital format (e.g., $\mathrm{CD}$ or diskette), but not allow the student access to the Internet. Another possible approach is to allow students access to digital sources of information on the web, but not to other individuals. Up to this point in time, we have consciously chosen to restrict our students to information we directly supply during the exam period.

With regard to some accounting and AIS-related course material, computerized testing may be the only way that professors can truly know how well students can complete complex professional tasks in a digital environment. This does not mean that the SOCT approach is simple to administer or without its share of concerns. However, the planned adoption of computerized testing methodologies for the Uniform CPA exam by the AICPA provides further evidence of the importance and pervasiveness of PC-based testing methodologies. It is important from both a professional career point of view, as well as a future examination point of view (e.g., GMAT and CPA exams), that our graduates are able to confidently work on a daily basis in a computerized environment. We feel one of the best methods of encouraging our students to become proficient in using the computer for professional purposes is to require them, where appropriate, to utilize the computer during class examinations. This, in turn, provides a direct incentive for the student to become more familiar with using the computer as an invaluable tool for business purposes.

This paper has described the use of synchronous onsite computerized testing techniques to further encourage student computer literacy and provide an appropriate matching of assessment techniques with course content. The SOCT environment has proven to be invaluable in assessing students for certain AIS related material. The SOCT examination method provides a relatively high degree of confidence that each student has obtained at least the desired minimum level of proficiency in utilizing the computer in an efficient and effective manner in handling reasonably complex customized accounting and business transaction processing systems within a relational database environment. SOCT techniques may not be necessary, or even advisable, for some courses or types of subject matter, but computerized testing techniques have proven to work extremely well for assessing combined cognitive and practical computer abilities regarding certain critical AIS-related information and processes.

\section{Suggestions for Future Research}

We have provided our rationale for the use of synchronous onsite computerized testing techniques to provide a better match of assessment to curriculum for various types of accounting and information systems courses. 
Future research can explore a more precise delineation of which specific courses and subject matter are most appropriate for the utilization of SOCT techniques. In addition, research can be conducted to more precisely identify and quantify the specific advantages achieved through the use of SOCT techniques. One method of achieving this could be through an experimental setting in which one group of students complete a required course (e.g. Personal Computers or AIS) that utilizes SOCT techniques, while a second group of students take the same course using traditional testing methodologies. The two groups can then be examined at a later date to evaluate the extent of their respective knowledge and abilities retained. This evaluation could be conducted using performance results in future required courses, e.g. Database. Alternatively, the researcher could administer another type of independent testing mechanism such as the Microsoft Certification examinations. The goal of this stream of research would be to more precisely identify and quantify the advantages, and possible disadvantages, of implementing a testing methodology that is destined to become much more prevalent in many types of education.

\section{References}

1. Accounting Education Change Commission, "Objectives of education for accountants: Position statement number 1," Issues in Accounting Education, fall, pp. 307-312, 1990.

2. Accounting Education Change Commission, "Position and issues statement of the accounting education change commission," American Accounting Association, Sarasota, Florida, 1996.

3. American Institute of Certified Public Accountants (AICPA), "AICPA core competency framework for entry into the accounting profession," http://www.aicpa.org/edu/corecomp.htm, 21 May 2001.

4. Exposure Draft. "Proposed structure and content specifications for the uniform CPA examination," February 28, 2001.

5. American Accounting Association (AAA), "Report of committee on accounting instruction in electronic data processing," Accounting Review, April, pp. 215-220, 1959.

6. "Report of committee on accounting systems instruction," Accounting Review, July, pp. 715-720, $\overline{1964 .}$

7. "Report of the 1968-69 committee on the role of the computer in accounting education," Accounting Review, supplement, pp. 29-43, 1970.

8. "Future accounting education: Preparing for the expanding profession," (Committee on the Future Structure, Content, and Scope of Accounting Education), Issues in Accounting Education, spring, pp. 168$195,1986$.

9. __ Accounting Education: Charting the Course through a Perilous Future. (W. Steve Albrecht and Robert J. Sack) Accounting Education Series, Volume No. 16, American Accounting Association, Sarasota, Florida, 2000.

10. Arthur Anderson \& Co, Arthur Young, Coopers \& Lybrand, Ernst \& Whinney, Peat Marwick \& Co, Price Waterhouse, Perspectives on education: Capabilities for success in the accounting profession, New York, 1989.

11. Cardwell, K., “Electronic assessment,” Learning \& Leading with Technology (27:7) April, pp. 22-26, 2000.

12. Davis, P., "What computer skills do employers expect from recent college graduates?" Technological Horizons in Education Journal, pp. 74-78, 1997.

13. Elliott, R. K. and D. M. Pallais, “Are you ready for new assurance services?” Journal of Accountancy, June pp. 47-51, 1997.

14. Jensen, B., "Using asynchronous network courses to bridge gaps in the teeth of a university curriculum with imported gold: bridgework may be optimally effective only by incurring high labor expenses," Working Paper, Trinity University, http://www.trinity.edu/rjensen/255wp.htm, 21 May 2001.

15. Siegel, G. and J. E. Sorensen, "What corporate America wants in entry-level accountants," Management Accounting, September, pp. 24-31, 1994.

16. Stager, S.F. and D. Mueller, "Computer use in classroom testing," Educational testing: issues and applications 16, pp. 245-277, 1991.

17. Thelwall, M., "Computer-based assessment: a versatile educational tool”" Computers \& Education 34, pp. 37-49, 2000.

18. Treadway, R., “An integrated computerized instructional systems for classroom and Lab," ED 425736 IR 019 224, Educational Digest, Paper presented at the ASCUE Proceedings, Greensboro, NC, 1998. 
(The authors would like to thank the participants of the Semantic Modeling of Accounting Phenomenon (SMAP) seminar at the American Accounting Association annual meeting in San Diego (August 1999) as well as the participants at the Accounting Information Systems (AIS) Educators Conference in Denver (July/August 2000) for their comments and suggestions for improvements.) 